\title{
Vascularised fibular graft in the management of non-union of fracture shaft of ra- dius: a less ventured entity
}

\author{
Tapas K. Panigrahi, Ramesh C. Maharaj and Debi P. Nanda
}

Ghana Med J 2020; 54(4): 284-286 doi: http://dx.doi.org/10.4314/gmj.v54i4.13

\author{
Department of Orthopaedics, Sriram Chandra Bhanja Medical College, Cuttack, Odisha, India
}

Corresponding author: Debi P Nanda

E-mail: id-drdebiortho@gmail.com

Conflict of interest: None declared

\begin{abstract}
SUMMARY
Introduction: Non-union of the radius and ulna is a major complication of forearm fractures, accounting upto $10 \%$ of all forearm fractures. Multiple modalities are available for the treatment of non-union. Vascular grafts are a less sought-after surgical choice owing to the need of expertise and skills of surgeons. We discuss a case of gap non-union of fracture shaft radius treated with vascular fibula graft.

Case Report: We describe a case of $45 \mathrm{yr}$ old lady with closed fracture of both bones of left forearm.

She underwent open reduction and internal fixation with 3.5 small DCP (6 hole) two days following trauma. On subsequent follow up in 6 months the radius fracture showed signs of infected non-union with osteolysis at screw sites while the ulnar side showed signs of satisfactory union. The patient underwent debridement with implant removal and osteosynthesis with vascularised fibula for gap non-union as second stage. 3 and 6 months follow up showed improvement in DASH score as well as VAS score and fair return of regular activity.
\end{abstract}

Conclusion: In management of gap non-union of Shaft radius with gap $(>6 \mathrm{~cm})$ vascularised fibular graft provides excellent functional outcome with far less donor site complications.

Keywords: radius fractures, fracture fixation, internal, fibula, locked dynamic compression plate Funding: None declared

\section{INTRODUCTION}

Non-union rates after screw and plate fixation of diaphyseal fractures of forearm are upto $10 \% .{ }^{1}$ Fracture gapping after $3.5-\mathrm{mm}$ screw and plate application occurs because of inadequately followed principles of fixation which will prevent primary bone healing and possibly result in non-union. Furthermore, around one-third of non-union occur in the presence of a deep surgical site infection. ${ }^{2}$ Various treatment modalities exist which include cortico-cancellous bone graft from iliac crest, illizarov method, and vascularised and nonvascularised autologous bone graft followed by fixation with 3.5 Dynamic Compression Plate(DCP).

It has been concluded in studies that technique of bone block grafting to correct diaphyseal defects of the radius or ulna is relatively easy to perform and has a high success rate ${ }^{3}$ but the massive amount of graft required for an $8 \mathrm{~cm}$ gap is associated with multiple donor sites complication. ${ }^{4}$ Illizarov method being cumbersome in forearm with time to recovery being long was not opted for. ${ }^{5}$ Free vascularised fibular grafting(FVFG) is a successful form of treatment for large bony defects and use of modern techniques of fixation does not affect the risk of non-union when compared with traditional forms of fixation. ${ }^{6}$ Here we discuss a case pf gap non-union of radius treated with FVFG and fixation with 3.5 locking DCP.

\section{CASE REPORT}

A 45yr old lady suffered from a road traffic accident and sustained a closed diaphyseal fracture of both the bones forearm on left side. She underwent Open reduction and internal fixation of both the bones after 2 days following trauma with 3.5 Small DCP(6 hole). On subsequent follow up at 6 months with her primary surgeon it was found that there was osteolysis at the radius site while the ulna showed good signs of union. She was complaining of persistent pain (VAS Score-4) and unable to do routine activities with the involved limb. We evaluated her radiographs and did routine haematological tests. The parameters suggested there is some deep tissue infection (Raised Erythrocyte Sedimentation Rate $\{\mathrm{ESR}\}$ and Creactive protein $\{C R P\})$ but the wound was healthy with healthy scar. 


\section{Case Report}

The patient was planned for staged surgery. First stage for implant removal with debridement, lavage of fracture site with culture sensitivity studies. Second stage for osteosynthesis with FVFG with plate once the acute phase reactants settled down. After a period of 2 months we again admitted the patient and did the routine investigations. As it was expected there was near normalcy of the parameters of infection like ESR, CRP .

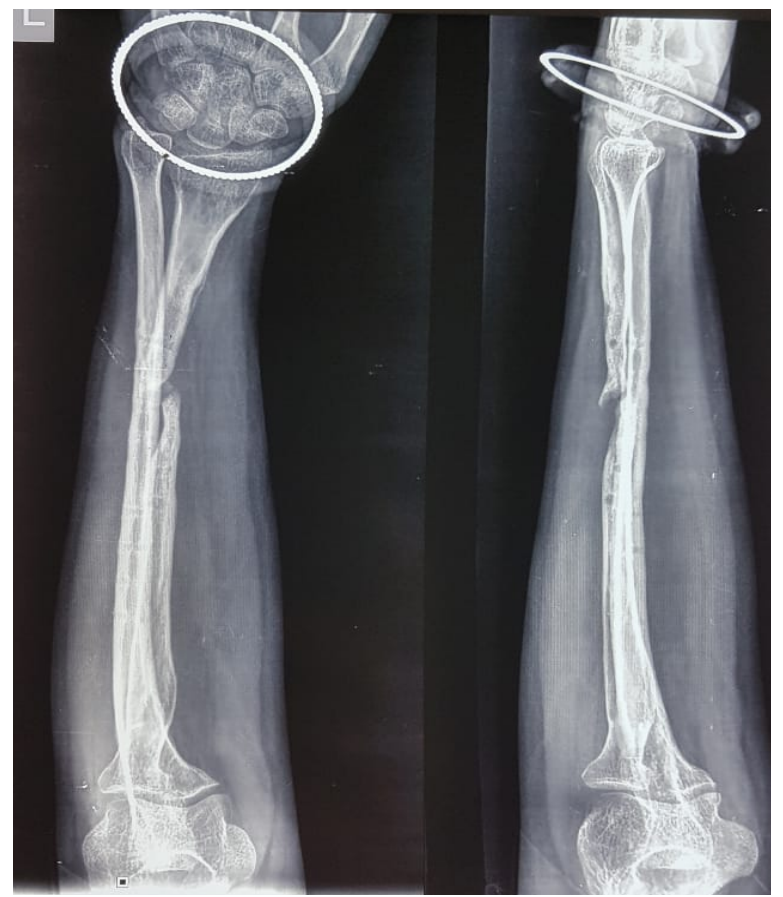

Figure 1 Initial preoperative radiograph

We diagnosed this as a case of gap non-union of shaft radius as evident from radiological investigation (Figure 1) and described all the treatment alternatives to the patient. After obtaining all the necessary consent we decided to do a free vascularised fibular grafting and fixation with a locking 3.5 small DCP. (12 hole)

We approached the radius through the previous incision site and freshened the atrophic ends of radius and finally found the gap to be $8 \mathrm{~cm}$ (Figure 2A). The ipsilateral fibula was harvested in its middle $2 / 3^{\text {rd }}$ taken as a pedicle with the peroneal artery, which arises from the posterior tibial artery, 3 to $4 \mathrm{~cm}$ distal to its bifurcation into the anterior and posterior tibial arteries(Figure 2B,2C).It was fixed in the recipient site with the use of a 3.5 locking Dynamic Compression Plate(Figure 2D). With the aid of a microscope and the use of 8-0 polyamide suture, the feeder artery for the graft was anastomosed to the radial artery in end to end manner. Both the donor and recipient site was closed after thorough wound irrigation and drains in situ.
Post-operative slabs were given both in upper and lower limb.
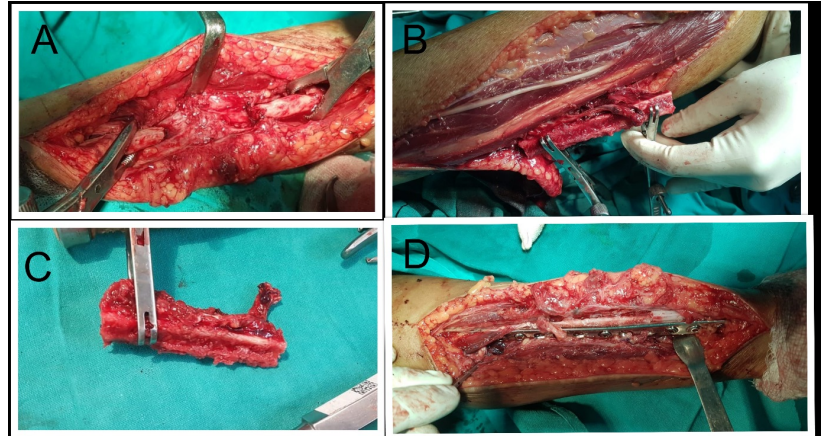

Figure 2-Intra operative pictures :(A) The radial gap of 8 $\mathrm{cm}$. (B) Clamping and harvesting of fibular graft. (C) Final FVFG with the arterial loop. (D)Fixation with 3.5 Locking DCP.
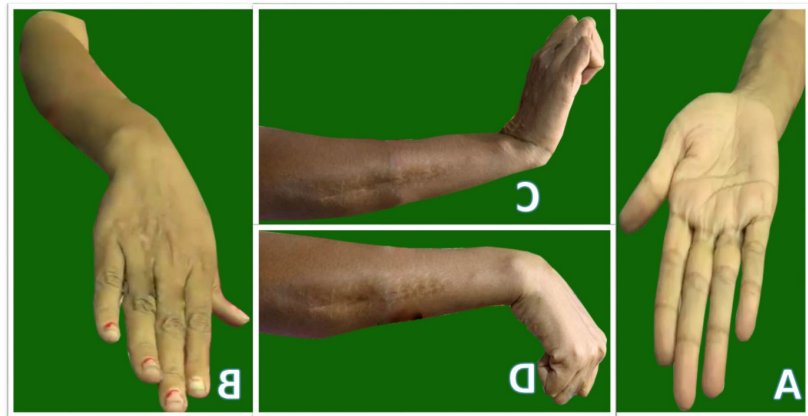

Figure 3 Follow up after 6 months: (A) Supination (B) Pronation (C) Extension (D)Flexion

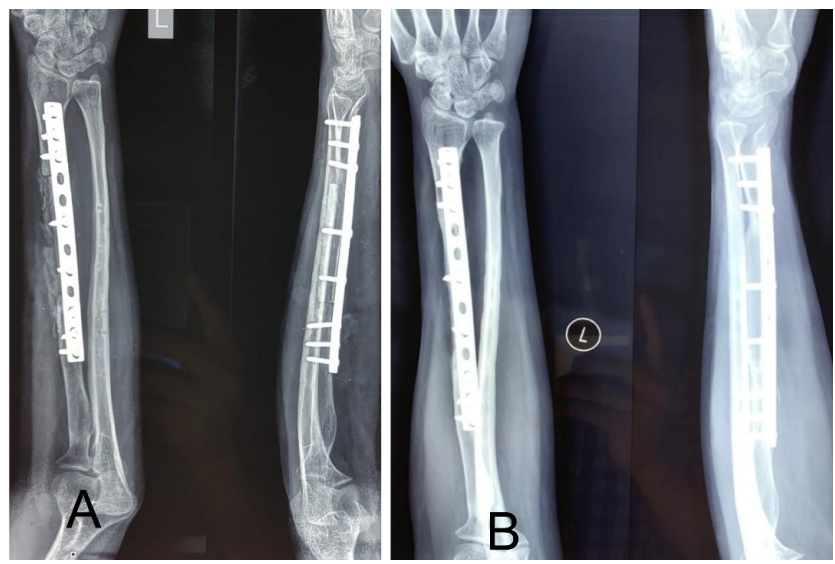

Figure 4 Post-operative radiographs: (A) Immediate Post op (B) 6 months follow up

The patient was followed up monthly with radiographs and serum parameters of infection. She was allowed to do free range of movement exercise for elbow and wrist but non weight lifting. At 6 months there is satisfactory movement in elbow and wrist (Figure 3 ) and the graft is completely healed (Figure 4). 


\section{DISCUSSION}

Non unions of both bone of forearm is not so uncommon and among that gap non-union of any single bone is very rare. While iliac crest grafting is mostly preferred by surgeons it is associated with a lot of donor site morbidities. Other methods such as Radialisation of Ulna in Post Infective Gap Non-union Radius leads to limitation of movements due to single bone construct.7 In defects greater than $6-8 \mathrm{~cm}$, vascularized grafts have been proposed to have significant advantages over conventional grafts. 8 It has been recommended that the vascularized fibular graft to be used in patients who have intractable non-union that have failed to respond to conventional bone grafting or who have large bone defects $(>6 \mathrm{~cm}) .9$ Fibula being not a principal transmitter of body weight in lower limb doesn't affect the gait or leg functions and movement.

\section{CONCLUSION}

Though a procedure of expertise free vascularised fibular grafting should always be borne in mind while treating gap non unions of forearm to give satisfactory movement and function to the patient's affected limb.

\section{REFERENCES}

1. Streubel PN, Pesántez RF. Diaphyseal fractures of the radius and ulna. In: Court-Brown CM, Heckmann JD, Mcqueen MM, Ricci WM, Tornetta III P, editors. Rockwood and Green's Fractures in Adults. Philadelphia: Wolters Kluwer Health; 2015. p. 1170.

2. Anderson LD, Sisk D, Tooms RE, Park WI 3rd. Compression-plate fixation in acute diaphyseal fractures of the radius and ulna. J Bone Joint Surg Am. 1975;57(3):287-297.

3. Barbieri CH, Mazzer N, Aranda CA, Pinto MM. Use of a bone block graft from the iliac crest with rigid fixation to correct diaphyseal defects of the radius and ulna. J Hand Surg Br. 1997;22(3):395-401. doi:10.1016/s0266-7681(97)80411-1

4. Laurie SW, Kaban LB, Mulliken JB, Murray JE. Donor-site morbidity after harvesting rib and iliac bone. Plast Reconstr Surg. 1984;73(6):933-938. doi:10.1097/00006534-198406000-00014

5. Ilizarov GA. Osnovnye printsipy chreskostnogo kompressionnogo i distraktsionnogo osteosinteza [Basic principles of transosseous compression and distraction osteosynthesis]. Ortop Travmatol Protez. 1971;32(11):7-15.

6. Houdek MT, Bayne CO, Bishop AT, Shin AY. The outcome and complications of vascularised fibular grafts. Bone Joint J. 2017;99-B(1):134-138. doi:10.1302/0301-620X.99B1.BJJ-2016-0160.R1

7. Yadav K, Kumar V, Singh A. Radialisation of Ulna in Post Infective Gap Non-union Radius-a Viable Reconstruction Option. Trauma Acute Care. 2017;Vol.2 No.4: 49.

8. Weiland AJ, Moore JR, Daniel RK. Vascularized bone autografts. Experience with 41 cases. Clin Orthop Relat Res. 1983;(174):87-95.

9. Adani R, Delcroix L, Innocenti M, Marcoccio I, Tarallo L, Celli A et al. Reconstruction of large posttraumatic skeletal defects of the forearm by vascularized free fibular graft. Microsurgery. 2004;24(6):423-429. doi:10.1002/micr.20067 